\title{
The intramolecular aldol condensation of 3-oxocyclohexaneacetaldehydes: a useful tool in the synthesis of natural products
}

\author{
Luisa Maria Migneco, Francesca Leonelli, and Rinaldo Marini Bettolo* \\ Dipartimento di Chimica and Istituto di Chimica Biomolecolare del CNR, Sezione di Roma \\ Università degli Studi di Roma "La Sapienza", P.le Aldo Moro 5, BOX n. 34 ROMA 62, I-00185 \\ Roma, Ital) \\ E-mail: rinaldo.marinibettolo@uniroma1.it
}

Dedicated to Professor Sándor Antus on his $6^{\text {th }}$ birthday

(received 23 Dec 03; accepted 21 Apr 04; published on the web 28 Apr 04)

\begin{abstract}
The intramolecular aldol condensation of 3-oxocyclohexaneacetaldehydes leading to $C(6)$ epimeric mixtures of 6-hydroxybicyclo[2.2.2] octan-2-ones is reviewed. Both steps, the preparation of the 3-oxocyclohexaneacetaldehyde and its cyclization were examined, as well as applications to the synthesis of natural products.
\end{abstract}

Keywords: 3-Oxocyclohexaneacetaldehydes, preparation, intramolecular aldol condensation

\section{Introduction}

1. Preparation of the 3-oxocyclohexaneacetaldehyde moiety

1.1. General remarks

1.2. Methodologies adopted

2. Cyclization of the 3-oxocyclohexaneacetaldehyde moiety

2.1.Reaction conditions

2.2.Endo/exo products distribution under kinetic and thermodynamic conditions

2.3.Factors controlling the equilibrium endo/exo product distribution

3. Applications to the synthesis of natural products

3.1. Preparation of the bicyclo[2.2.2] octanol moiety

4. Conclusions 


\section{Introduction}

The intramolecular aldol condensation of a 3-oxocyclohexaneacetaldehyde, leading to a $\mathrm{C}(6)$ epimeric mixture of 6-hydroxybicyclo[2.2.2] octan-2-ones $^{1}$ (Scheme 1), was first described in 1963 by Bell and Ireland in the frame of synthetic studies addressed to the alkaloid atisine. ${ }^{2 a}$

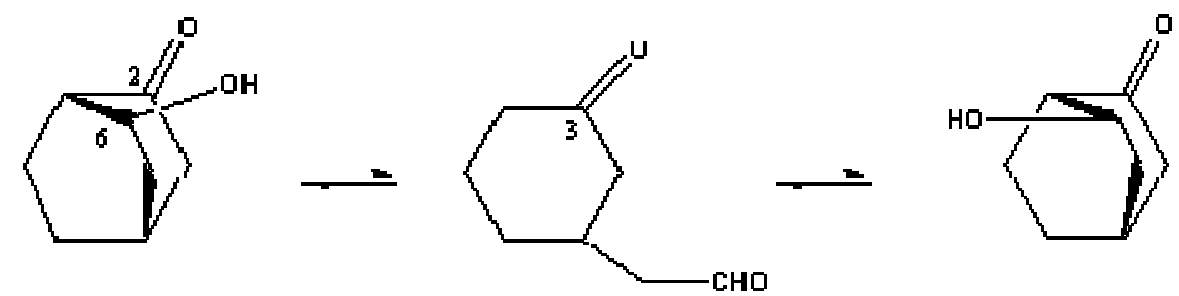

6-endo-hydroxybicyclo[2.2.2.]octan-2-one

6-exo-hydroxybicyclo[2.2.2.]octan-2-one

\section{Scheme 1}

Since then this reaction was used many times. An array of examples is reported in Scheme 2.

a)<smiles>O=C1C=C2CCCC[C@H]2CC1</smiles>

b)<smiles>O=C1C=C2C[C@@H]3CCC2[C@@H]3C1</smiles>

c)<smiles>O=C1CCCC2=C1CCCC2</smiles>
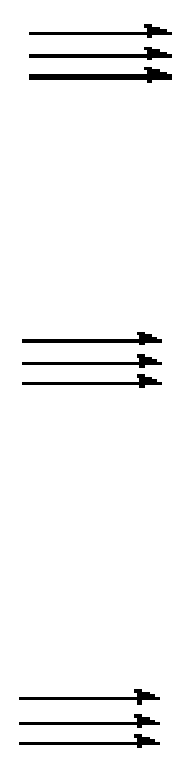<smiles>O=CC[C@@]12CCCC[C@H]1CCC(=O)C2</smiles><smiles>[CH2-]</smiles><smiles>C[C@H]1CCCC[C@H]1C</smiles>
ref. $2 f$<smiles>O=CC[C@@H]1[C@@H]2CC[C@@H]3C[C@@H]1[C@@H](CC3=O)C2</smiles>
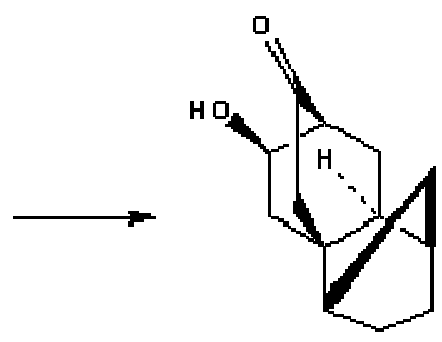

ref. $\mathbf{2 i}$<smiles>O=CCC12CCCCC1C(=O)CCC2</smiles><smiles>C[C@@]12CCCC[C@@]13CC[C@@H]2C(=O)C3=O</smiles>

ref. $2 \mathbf{r}$ 
d)

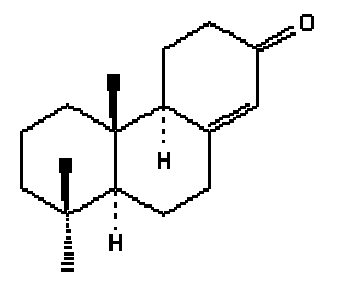

e)<smiles></smiles>

f)

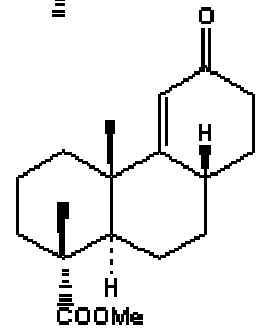

g)

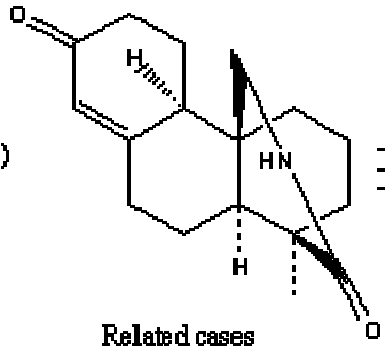

Related cases<smiles>C#CC=CCC[C@]1(C)CCC[C@]2(C)[C@H]3CCC(=O)C[C@@]3(CC=O)CC[C@]12C</smiles><smiles>C#C</smiles><smiles>C[C@@H]1CCC[C@]2(C)[C@H]1CC[C@]1(CC=O)CC(=O)CC[C@@]12C</smiles>

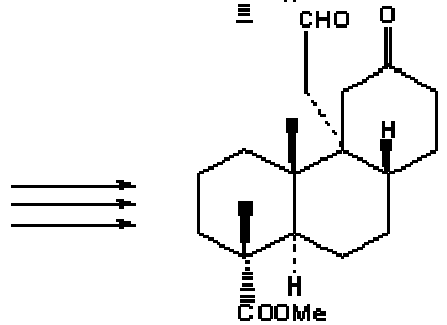<smiles>C#CC=C</smiles>

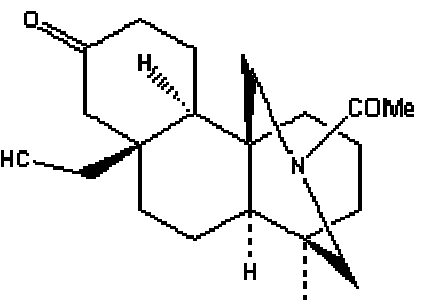

h)

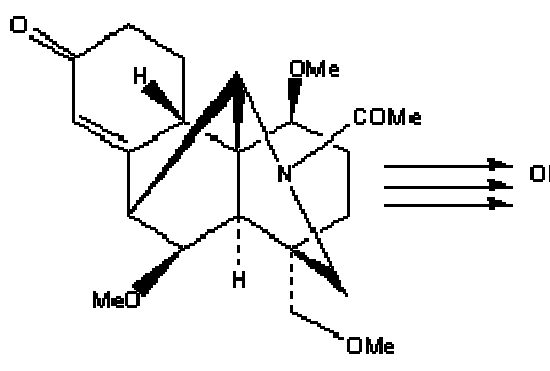
$\mathrm{OHC}$

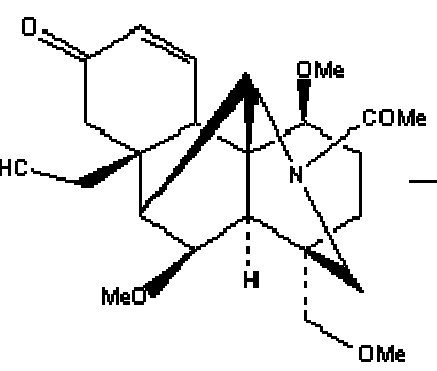

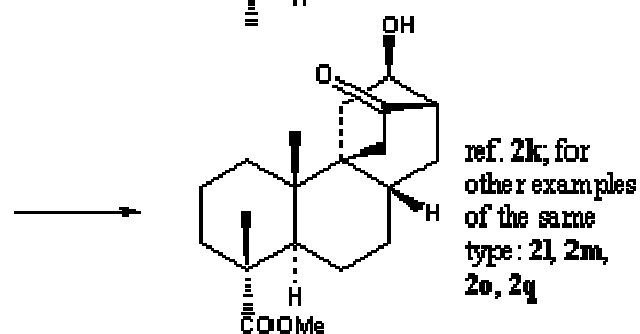

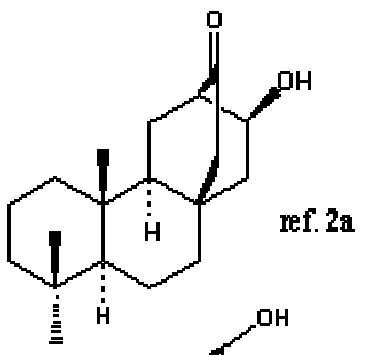

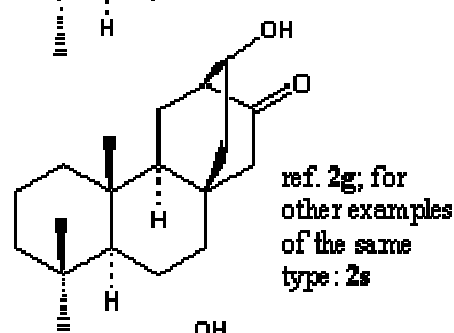

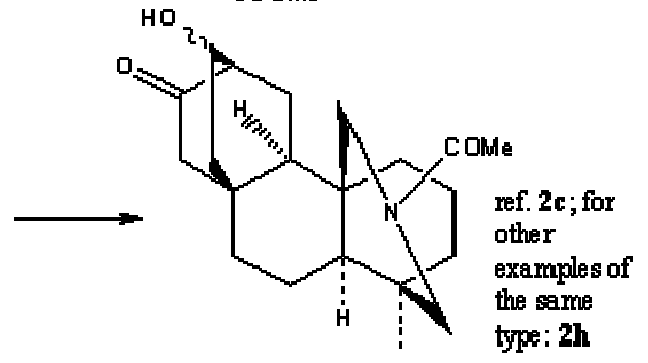<smiles>CC1=CC(=O)CC[C@]1(C)[C@H](N)CCCC(=O)O</smiles>

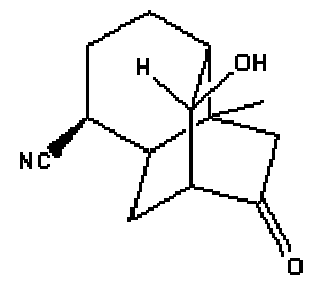

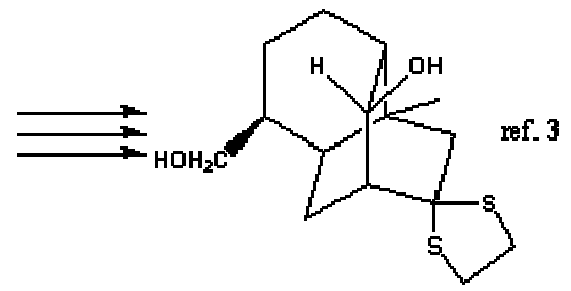

Scheme 2 
The importance of this intramolecular process stems from the fact that it leads to a bicyclo[2.2.2] octane system, a moiety present in a number of natural products or intermediates in their synthesis.

Besides, a feature very advantageous in view of further elaboration is that the bicyclo[2.2.2] octane system emerges from the condensation substituted at $\mathrm{C}(2)$ and $\mathrm{C}(6)$ with oxygenated functions at different oxidation levels $[\mathrm{HO}-\mathrm{C}(6)$ and $\mathrm{O}=\mathrm{C}(2)] .{ }^{4}$ For reasons which will be explained in the sequel, the $\mathrm{HO}-\mathrm{C}(6)$ in the major epimer is endo oriented.

There are two crucial steps in the process of constructing a 6-hydroxybicyclo[2.2.2] octan-2one by intramolecular aldol condensation:

a) the preparation of the 3-oxocyclohexaneacetaldehyde moiety;

b) its cyclization.

\section{Preparation of the 3-oxocyclohexaneacetaldehyde moiety}

\subsection{General remarks}

The 3-oxocyclohexaneacetaldehyde moieties were prepared from a 2-cyclohexen-1-one installing at $\mathrm{C}(3)$ by various means a formylmethyl side chain. ${ }^{5}$

This step is of crucial importance since, depending on the configuration of the newly created stereogenic center at C(3), diastereomeric products might be obtained. See for instance entries d) and e) in Scheme $2^{6}$

\subsection{Methodologies adopted}

The most adopted methods for the preparation of 3-oxocyclohexaneacetaldehydes from a 2cyclohexen-1-one are the Claisen rearrangement of the derived vinylethers ${ }^{2 \mathrm{a}, 2 \mathrm{~d}}$ and the allene photoaddition. $^{2 \mathrm{~b}-\mathrm{c}, 2 \mathrm{f}-\mathrm{o}, 2 \mathrm{q}-\mathrm{s}}$

The Claisen rearrangement approach is rather lengthy and suffers the loss of the oxygen function at $C(1)^{5}$ and its not fully regioselective reintroduction. As an example, Scheme 3 shows the preparation of the 3-oxocyclohexaneacetaldehyde key intermediate in the Ireland synthesis of kaurene $^{2 \mathrm{~d}}$ via Claisen rearrangement.
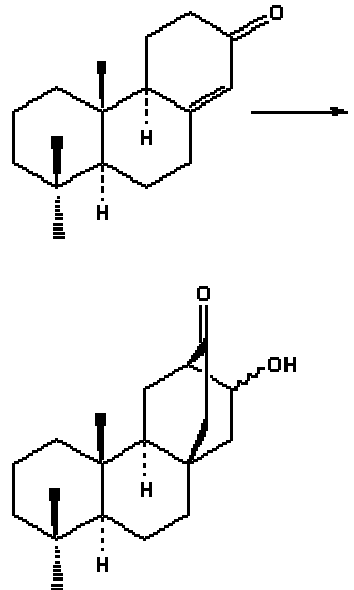

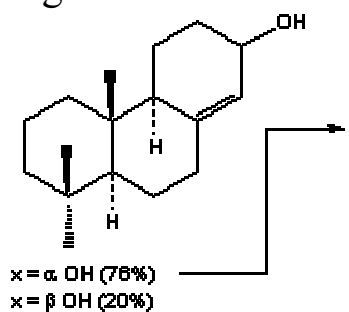

$x=\mathrm{OH}(20 \%)$
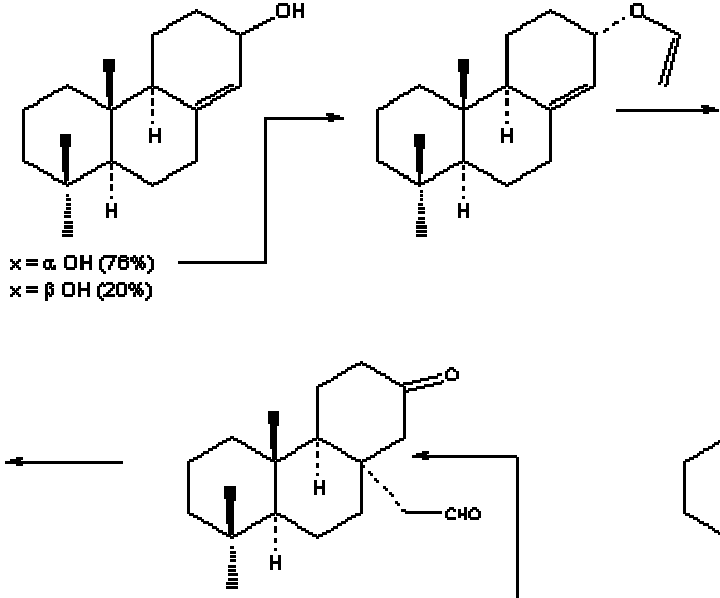
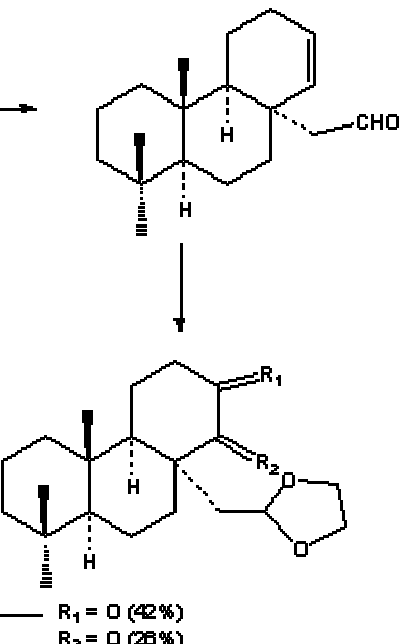

\section{Scheme 3}


The allene photoaddition ${ }^{7}$ is a very efficient and clean methodology suitable also for hindered 2-cyclohexen-1-ones. A further advantage of the latter methodology is its high stereoselectivity in the cases described. An example of the allene photoaddition reaction applied to obtaining the 3-oxo-cyclohexaneacetaldehyde intermediate in the Wiesner synthesis of atisine ${ }^{2 \mathrm{c}}$ is illustrated in Scheme 4.
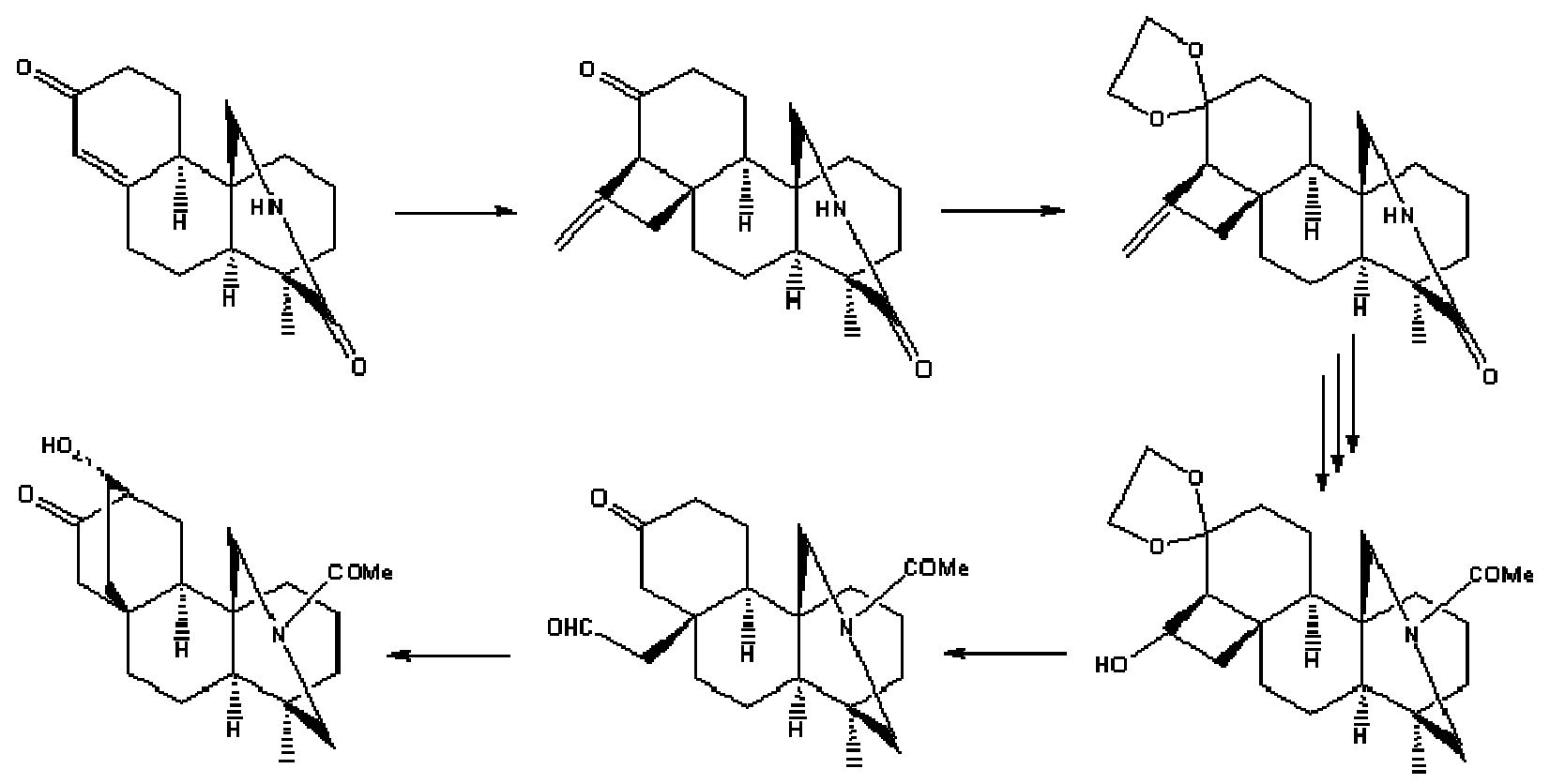

\section{Scheme 4}

In the case of the simplest 3-oxocyclohexaneacetaldehyde (Scheme 5), the C(3) two carbon side chain was introduced on 2-cyclohexen-1-one exploiting the classical diethylmalonate Michael addition, ${ }^{8}$ the same product was also obtained by the allylsilane Sakurai $\mathrm{TiCl}_{4}$-mediated conjugate addition. ${ }^{9}$

Following the latter methodology, different monocyclic 3-oxo-cyclohexaneacetaldehydes were also synthesized. ${ }^{10}$

\section{Cyclization of the 3-oxocyclohexaneacetaldehyde moiety}

As pointed out in the Introduction, in this intramolecular aldol reaction the 3-oxocyclohexaneacetaldehyde nucleophilic $\mathrm{C}(4)$ adds to the electrophilic side chain formyl $\mathrm{C}$-atom to give a $\mathrm{C}(6)$ epimeric mixture of 6-endo- and 6-exo-hydroxybicyclo[2.2.2]octan-2-ones which are in equilibrium through the parent ketoaldehyde (Scheme 1). ${ }^{11}$ 


\subsection{Reaction conditions}

The cyclization can be carried out under acidic or basic catalysis. Being, in most cases, the last step of a cascade process, the first step of which constituted by the unmasking of a hidden hydroxyketone, acidic or basic reactions conditions were chosen upon necessity. Thus the cyclization has been performed in aqueous mineral acid, ${ }^{2 \mathrm{a}, 2 \mathrm{e}}$ in aqueous mineral acids $(\mathrm{HCl}$, $\mathrm{H}_{2} \mathrm{SO}_{4}, \mathrm{H}_{3} \mathrm{PO}_{4}$ )/polar co-solvents (THF, acetone) mixtures, ${ }^{2 \mathrm{~b}-\mathrm{d}, 2 \mathrm{f}-\mathrm{h}, 2 \mathrm{l}-\mathrm{m}, 2 \mathrm{o}-\mathrm{p}, 2 \mathrm{r}-\mathrm{s}}$ in an organic acid $(p-\mathrm{TsOH})$ /apolar solvent $\left(\mathrm{CCl}_{4}\right)$ mixture, ${ }^{12}$ in methanolic $\mathrm{NaOH}^{2 \mathrm{j}}$ and in methanolic $\mathrm{THF} / \mathrm{NaOH}$ solution. $^{2 \mathrm{n}}$

\subsection{Endo/exo products distribution under kinetic and thermodynamic conditions}

The experimental reports related to above quoted cases do not disclose whether they were carried out under kinetic or thermodynamic conditions. Besides the analysis and separation of the epimeric product mixtures were not always performed. On these grounds a rigorous evaluation of the endo/exo epimers relative stability cannot be carried out.

Nevertheless obtaining the endo epimer as the major product after a long reflux in a $\mathrm{THF}$ /aqueous $\mathrm{HCl}$ mixture prompted Wiesner and coworkers to hypothesize that the endo epimer was the thermodynamic product. ${ }^{2 \mathrm{f}}$ This hypothesis was confirmed by the observation that when separately submitted to equilibration in $\mathrm{THF} / \mathrm{HCl}$ both the endo and exo epimers give mixtures in which the former predominates. ${ }^{13}$

If the endo product could on these grounds reasonably be considered the thermodynamic product, it was not known which epimer was the kinetic product. Carrying out the reaction at various times, it was shown later that the endo epimer is both the kinetic and thermodynamic product. $^{13}$

\subsection{Factors controlling the equilibrium endo/exo product distribution}

On Dreiding models inspection, H-bonding between the $\mathrm{C}(2)=\mathrm{O}$ and $\mathrm{HO}-\mathrm{C}(6)$ in the endo epimer appears unlikely. This assumption was confirmed by molecular mechanics (MM) calculations (Figure 1), X-ray (Figure 2) and NMR experiments (Figure 3). ${ }^{13}$
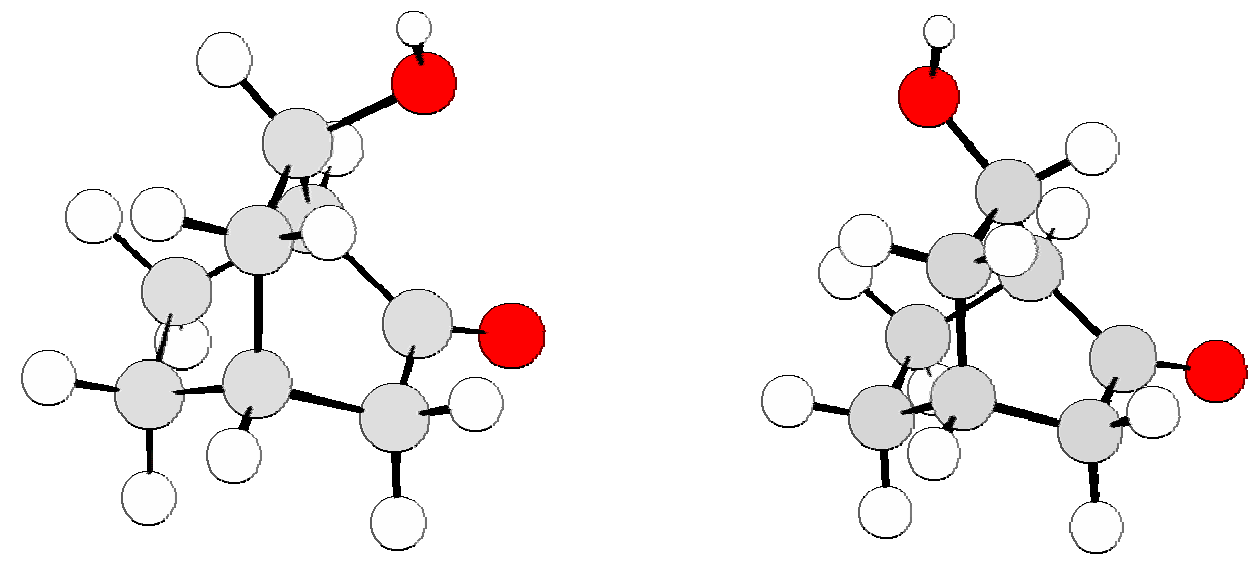

Figure 1. Optimized structures of 6-endo and 6-exo-hydroxybicyclo[2.2.2]octan-2-one. 
X-ray experiments, carried out on the related methyl 13-endo-hydroxy-16-oxo-17-noratisan18-oate (Figure 2), indicated the lack of the necessary spatial requirements for intramolecular $\mathrm{H}$ bonding. ${ }^{14}$
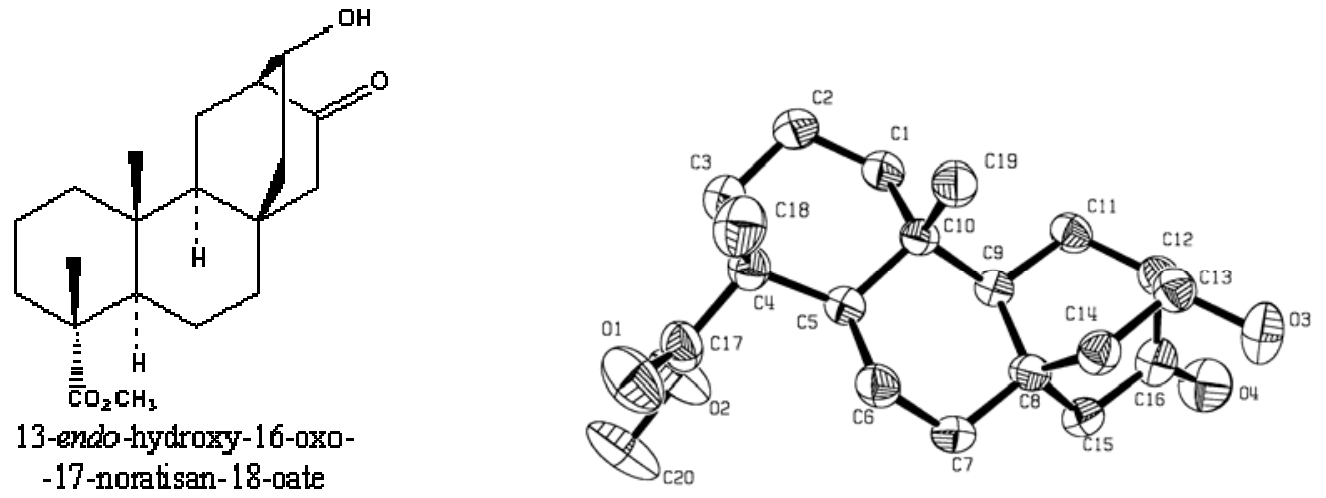

Figure 2. Structural formula and ORTEP-3 drawing of methyl 13-endo-hydroxy-16-oxo-17noratisan-18-oate.

${ }^{1} \mathrm{H}-\mathrm{NMR}$ experiments carried out on both epimers at different temperatures confirmed the lack of intramolecular H-bonding in 6-endo-hydroxybicyclo[2.2.2]octan-2-one, the chemical shift of the $\mathrm{HO}-\mathrm{C}(6)$ of both epimers approaching similar high field values on temperature increase.

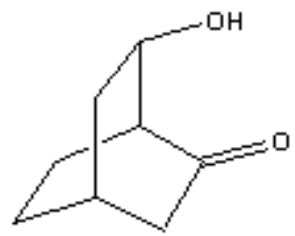

6-endo-hydroxybicyclo[2.2.2]octan-2-one

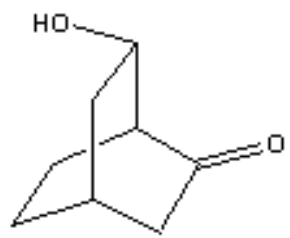

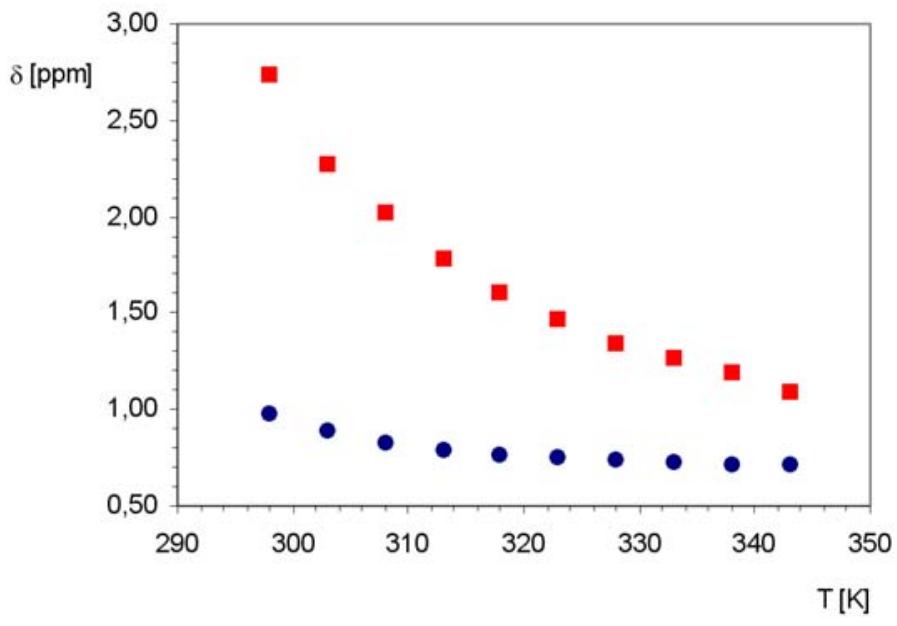

- 6-exo-hydroxybicyclo[2.2.2] octan-2-one

Figure 3. $\mathrm{HO}-\mathrm{C}(6)$ chemical shifts $\left(0.1 \mathrm{M}\right.$ in $\left.\mathrm{C}_{6} \mathrm{D}_{6}\right)$ for 6-endo-hydroxybicyclo[2.2.2] octan-2one ( $\square)$ and 6-exo-hydroxybicyclo[2.2.2]octan-2-one $(\bullet)$ at different temperatures.

Having ruled out an intramolecular H-bonding stabilization in the endo epimer, a geometric analysis to establish the destabilizing interactions in the exo epimer was carried out.

As could be inferred from molecular models, the $\mathrm{C}(1)-\mathrm{C}(6)-\mathrm{C}(5)-\mathrm{C}(4)-\mathrm{C}(8)-\mathrm{C}(7)$ six membered ring in both epimers is fixed in a boat conformation. Thus, in accord with Ouellette and Booth, ${ }^{15}$ who compared the interactions between an exo-configurated substituent at $\mathrm{C}(6)$ in 
bicyclo[2.2.2] oct-2-ene and the $\mathrm{H}_{\mathrm{exo}}-\mathrm{C}(7)$ to the 1,3 boat-axial interaction in cyclohexane, it was hypothesized that an interaction between the pseudo-axially oriented $\mathrm{HO}-\mathrm{C}(6)$ and the $\mathrm{H}_{\mathrm{exo}}-\mathrm{C}(7)$ might be present in the exo epimer. The interatomic distances values obtained by NOE difference spectra and MM calculations supported the hypothesis of a repulsive interaction between the two groups. From MM calculations resulted also that the endo epimer has a strain energy value 0.6 $\mathrm{kcal} / \mathrm{mol}$ lower than the exo one. ${ }^{13,16}$

\section{Applications to the synthesis of natural products}

As pointed out above, the intramolecular aldol condensation of the 3-oxocyclohexaneacetaldehydes was devised for the synthesis of natural products containing a bicyclo[2.2.2] octane moiety such as atisine, ${ }^{2 \mathrm{a}-\mathrm{c}}$ atisirene, ${ }^{2 \mathrm{~d}}$ trachylobane and related compounds. $2 \mathrm{~g}, 2 \mathrm{~s}$

It has also been applied to the synthesis of natural products containing a bicyclo[3.2.1]octane

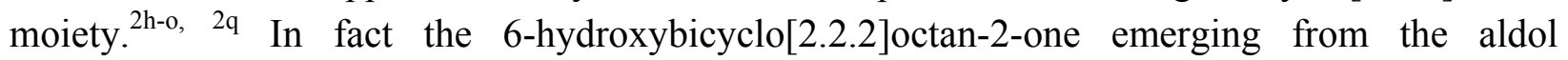
condensation after being converted into a suitably substituted bicyclo[2.2.2] octan-2-ol might undergo to a [2.2.2] $\rightarrow[3.2 .1]$ rearrangement. As known, the rearrangement proceeds with the migration of the $\mathrm{C}-\mathrm{C}$ bond antiperiplanar to the leaving group. Thus a different leaving group location and stereochemistry produces a different skeleton. Clarifying in this respect are the syntheses of the tetracyclic diterpenes maritimol, ${ }^{2 \mathrm{n}} \operatorname{aphidicolin}^{21,}{ }^{20} \operatorname{stemarin}^{2 \mathrm{k}}$ and 13 stemarene. $^{2 \mathrm{q}}$

\subsection{Preparation of the bicyclo[2.2.2]octanol moiety}

3.1.1 Bicyclo[2.2.2] ]octanols in which the hydroxy group is endo to C(2). ${ }^{4}$ This is the simplest and easiest case, because the hydroxy group in the final product has the same stereochemistry of $\mathrm{HO}-\mathrm{C}(6)$ of the major ketol (endo epimer) of the aldol condensation. Further elaboration of the parent 6-endo-hydroxybicyclo[2.2.2]octan-2-one gives then the desired compound (Scheme 5).
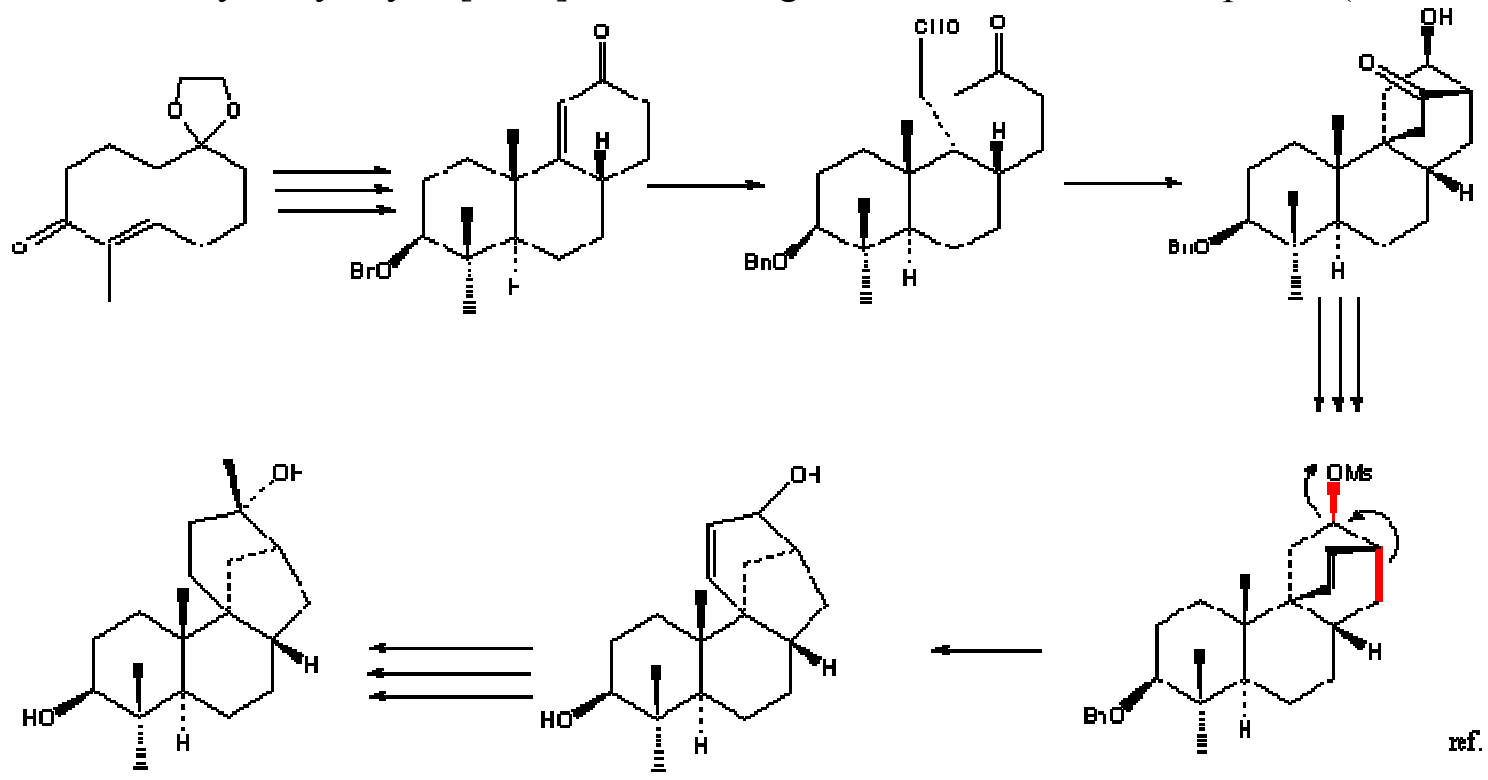

ref. 2n

Scheme 5 
3.1.2 Bicyclo[2.2.2]octan-2-ols in which the hydroxy group is endo to $\mathbf{C}(6){ }^{4}$ The needed bicyclo[2.2.2] octan-2-ol might be obtained from the parent 6-endo-hydroxybicyclo[2.2.2]octan2-one by protection of the endo $\mathrm{HO}-\mathrm{C}(6)$ followed by diastereoselective reduction of the $\mathrm{C}(2)=\mathrm{O}$ (Scheme 6) and elaboration, as required, of the protected $\mathrm{HO}-\mathrm{C}(6)$.

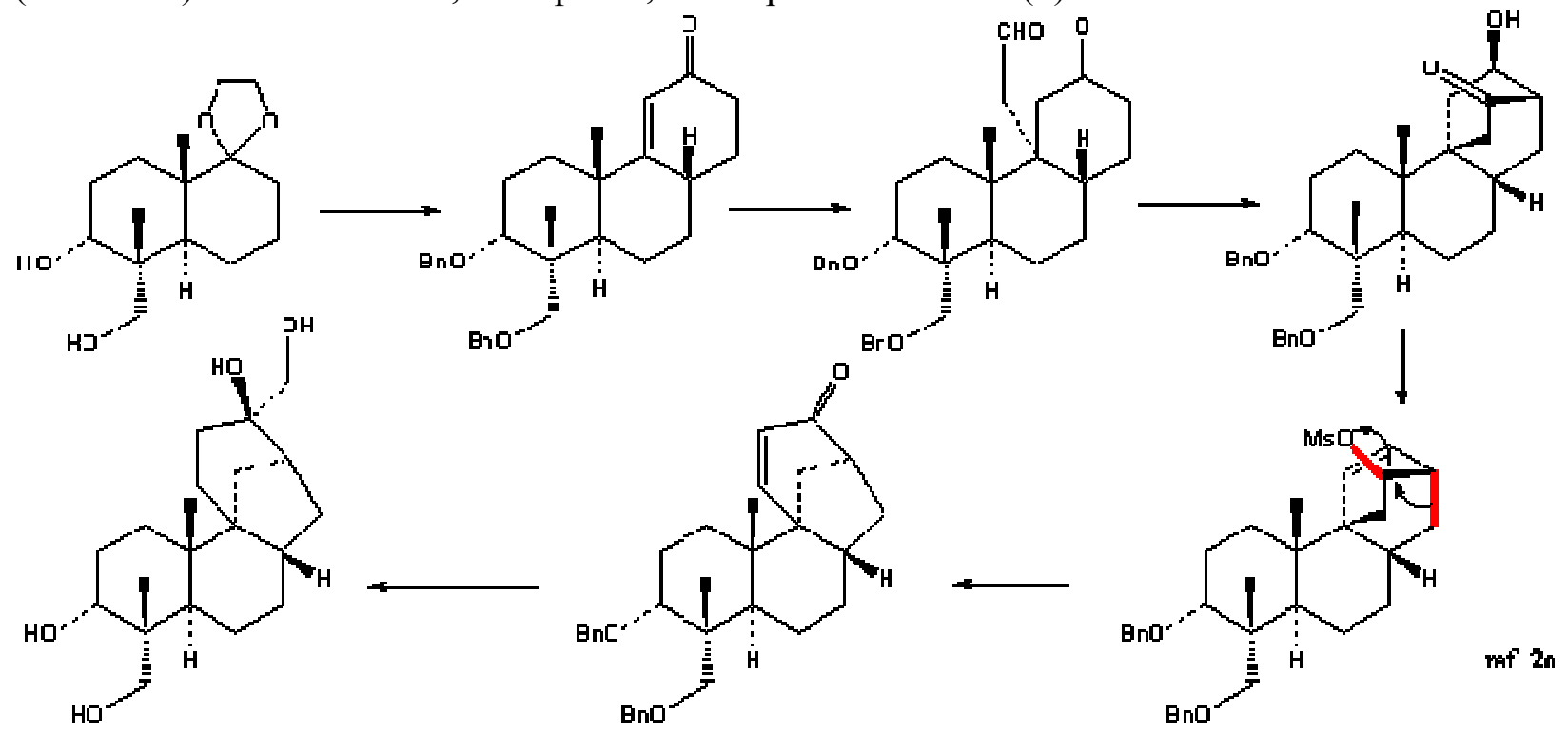

\section{Scheme 6}

3.1.3 Bicyclo[2.2.2]octanols in which the hydroxy group is exo to $\mathbf{C}(2){ }^{4}$ In this case the hydroxy group in bicyclo[2.2.2] octanol has the same stereochemistry of the HO-C(6) of the minor epimer (exo) of the aldol condensation, that is opposite to that of the $\mathrm{HO}-\mathrm{C}(6)$ of the major product (endo epimer) of the condensation. Three different tactics can be envisaged.

3.1.3.1 Deoxygenation (ethanedithiol, $\mathrm{BF}_{3}$, r.t.; Ni/Raney, $\mathrm{EtOH}$, reflux) of the parent 6-exohydroxybicyclo[2.2.2] octan-2-one gives the desired compound. ${ }^{18}$ Of course the previous nondiastereoselective step (the intramolecular aldol condensation) is a flaw in the whole synthetic sequence (Scheme 7).

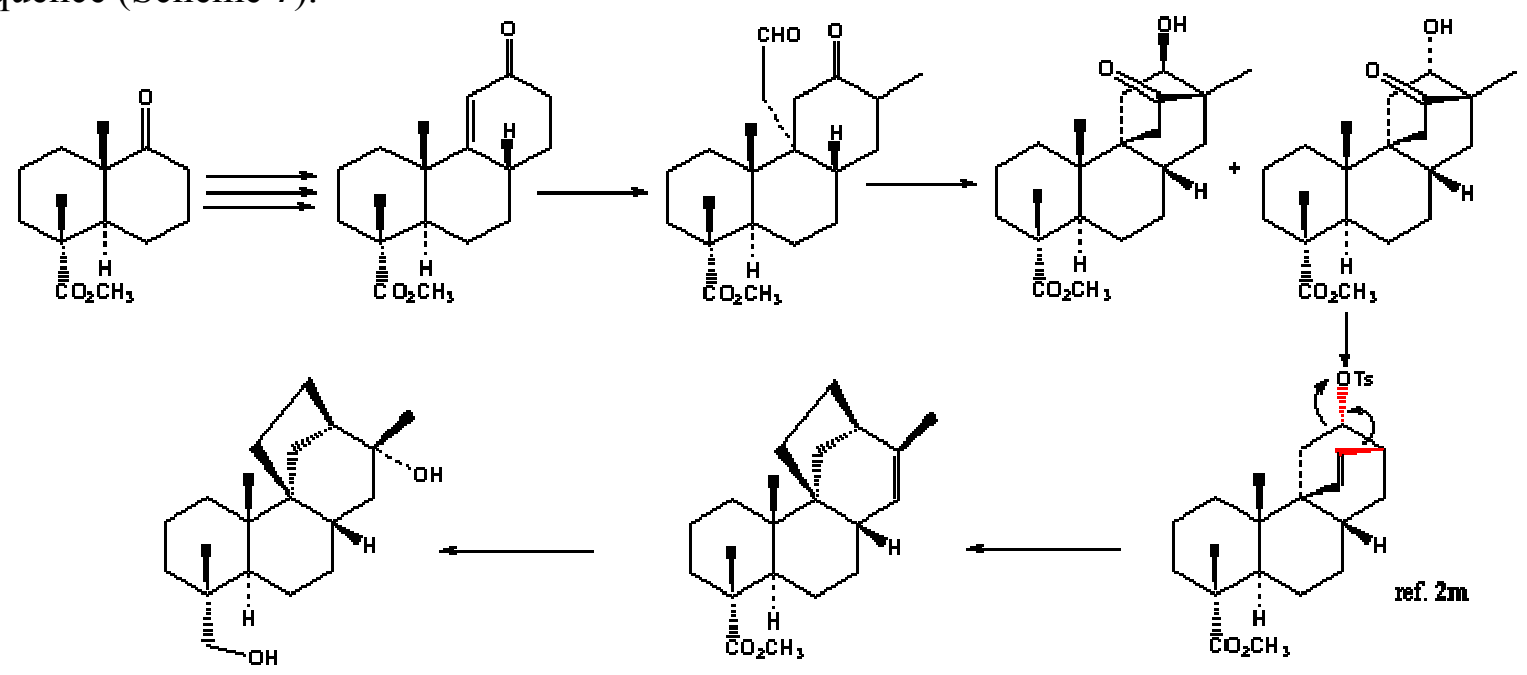

Scheme 7 
3.1.3.2 The 6-hydroxybicyclo[2.2.2] octan-2-ones mixture is separated, the minor 6-exohydroxybicyclo[2.2.2] octan-2-one collected and the major 6-endo-hydroxybicyclo[2.2.2]octan-2one re-submitted to equilibration. The equilibrium mixture is then again separated and the minor epimer again collected. Some cycles are required, as in the Mori synthesis of (+)-pinthunamide ${ }^{12}$ (Scheme 8).
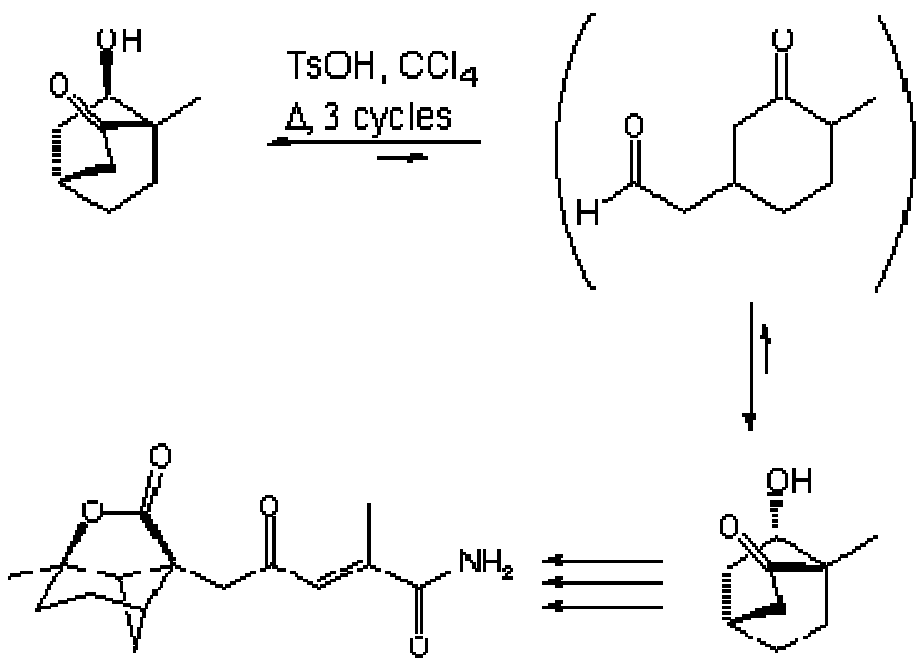

\section{Scheme 8}

3.1.3.3 Conversion of the 6-endo-hydroxybicyclo[2.2.2] octan-2-one into the corresponding tosylate and treatment of the latter with a tetraalkylammonium carboxylate to give a 6-exocarbalkoxybicyclo[2.2.2] octan-2-one $^{19}$ in which the exo ketol system is locked and therefore unable to equilibrate back to the more stable endo epimer.

a) Deoxygenation of the $\mathrm{SN} 2$ reaction product, followed by basic hydrolysis gives then the desired bicyclo[2.2.2] octan-2-ol (Scheme 9).

b) Recently, however, after R.S. Brown's disclosure that esters cleavage can be performed by methanolysis under non-basic conditions in the presence of $\mathrm{La}(\mathrm{OTf})_{3},{ }^{20}$ an alternative sequence, implying deprotection of the 6-exo-acetoxybicyclo[2.2.2] octan-2-one by methanolysis in the presence of $\mathrm{La}(\mathrm{OTf})_{3}$ to give a 6-exo-hydroxybicyclo[2.2.2] octan-2one followed by deoxygenation, as described above, was put to work, ${ }^{21}$ thus allowing to improve the obtaining of a key intermediate in the syntheses of 13-stemarene and 18deoxystemarin (Scheme 9). 
<smiles>CCC1C(C)C(=O)CCC12CCCC21CCCO1</smiles><smiles>C=[C+]C</smiles><smiles>C[C@H]1CCC[C@]2(C)CC[C@@H]1[C@@]1(C)CC(=O)CC[C@H]21</smiles>

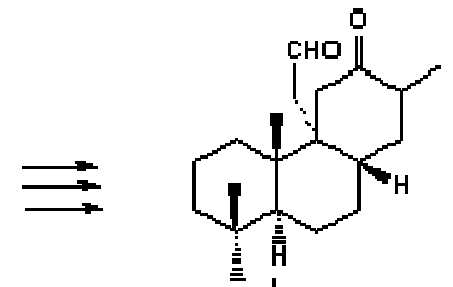
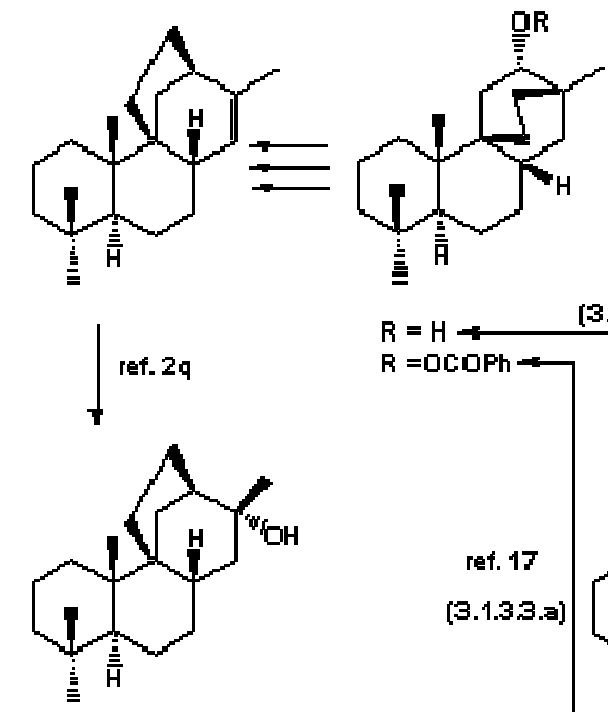

$[3.1 .3 .1]$

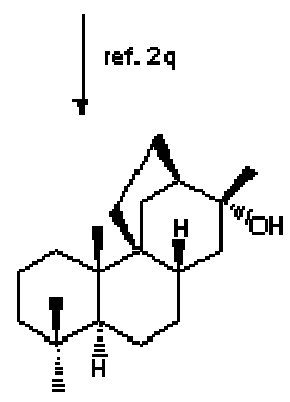

\section{Scheme 9}

\section{Conclusions}

The intramolecular aldol condensation of 3-oxocyclohexaneacetaldehydes leading to $\mathrm{C}(6)$ epimeric mixtures of 6-hydroxybicyclo[2.2.2] octan-2-ones has been reviewed. Both steps, the preparation of the 3-oxocyclohexaneacetaldehyde moiety and its cyclization were examined as well as the endo/exo distribution under thermodynamic conditions and the factors responsible for it.

Applications of this reaction and further elaborations of the condensation products into a bicyclo[2.2.2] octan-2-ol in the frame of the synthesis of natural products were also considered. From this review it appears that a) an $\alpha, \beta$-unsaturated cyclohexanone was always adopted as the starting material, b) only two methodologies (Claisen rearrangement and allene photoaddition) were chosen for the introduction of the formylmethyl side-chain in complex systems c) a way to obtain as a major product a 6-exo-hydroxybicyclo[2.2.2]octan-2-one by intramolecular aldol condensation of 3-oxocyclohexaneacetaldehyde has not been yet devised. 
The field is therefore still open to further investigations. We hope the reader might agree and find this review useful.

\section{Acknowledgements}

Financial support by Università degli Studi di Roma "La Sapienza" (Ateneo 60\%) and Ministero dell'Istruzione, Università e Ricerca (COFIN 2000 "Sintesi di Sostanze di Comunicazione Chirali" and COFIN 2002 "Aromi e Fragranze”) is gratefully acknowledged.

\section{References and Notes}

1. Only 6-hydroxybicyclo[2.2.2] octan-2-ones obtained by intramolecular aldol condensation of a 3-oxocyclohexaneacetaldehyde are taken into account.

2. (a) Bell, R. A.; Ireland, R. E. Tetrahedron Lett. 1963, 269. (b) Guthrie, R. W.; Philipp, A.; Valenta, Z.; Wiesner, K. ibid. 1965, 2945. (c) Guthrie, R. W.; Valenta, Z.; Wiesner, K. ibid. 1966, 4645. (d) Bell, R. A.; Ireland, R. E.; Partyka, R. A. J. Am. Chem. Soc. 1966, 31, 2530. (e) Mori, K.; Nakahara, Y.; Matsui, M. Tetrahedron 1972, 28, 3217. (f) Wiesner, K.; Tsai, T. Y. R.; Huber, K.; Bolton, S. Tetrahedron Lett. 1973, 1233. (g) Kelly, R. B.; Eber, J.; Hung, H. K. Can. J. Chem. 1973, 51, 2534. (h) Wiesner, K. Pure Appl. Chem. 1975, 41, 93. (i) Wiesner, K., Ho, P.; Liu, W.; Shanbhag, M. N. Can. J. Chem. 1975, 53, 2140. (j) Tsai, T. Y. R.; Tsai, C. S. J.; Sy, W. W.; Shanbhag, M. N.; Liu, W. C.; Lee, S. F.; Wiesner, K. Heterocycles 1977, 7, 217. (k) Kelly, R. B.; Harley, M. L.; Alward, S. J. Can. J. Chem. 1980, 58, 755. (1) Bravetti, D.; Marini Bettolo, R.; Lupi, A. Helv. Chim. Acta 1982, 65, 371. (m) Kelly, R. B.; Harley, M. L.; Alward, S. J.; Rej, R. N.; Gowda, G.; Mukhopadhyay, A.; Manchand, P. S Can. J. Chem. 1983, 61, 269. (n) Marini Bettolo, R.; Tagliatesta, P.; Lupi, A.; Bravetti, D. Helv. Chim. Acta 1983, 66, 760. (o) Marini Bettolo, R.; Tagliatesta, P.; Lupi, A.; Bravetti, D. ibid. 1983, 66, 1922. (p) Mori, K.; Nagano, E. Biocatalysis 1990, 3, 25. (q) Berettoni, M.; Marini Bettolo, R.; Montanari, V.; Prencipe, T.; Romeo, S. Helv. Chim. Acta 1991, 74, 1671. (r) Bartoletti, A.; Berettoni, M.; Catteruccia, F.; De Chiara, G.; Marini Bettolo, R.; Mastrangeli, C.; Scarpelli, R.; Tozzi, C.; Lamba, D. Gazz. Chim. Ital. 1996, 126, 223. (s) Berettoni, M.; De Chiara, G.; Iacoangeli, T.; Lo Surdo, P.; Marini Bettolo, R.; Montagnini di Mirabello, L.; Nicolini, L.; Scarpelli, R. Helv. Chim. Acta 1996, 79, 2035.

3. Niwa, H.; Hasegawa, T.; Ban, N.; Yamada, K. Tetrahedron 1987, 43, 825.

4. 6-hydroxybicyclo[2.2.2] octan-2-one numbering is used throughout.

5. 2-cyclohexen-1-one numbering is used throughout.

6. As far as stereochemistry of $\mathrm{C}(6)-\mathrm{OH}$ group in ketols is concerned, in Scheme 2 only the major epimer, if any and when clearly indicated by the Authors, is reported. 
7. (a) Wiesner, K. Tetrahedron 1975, 31, 1655. (b) Marini Bettolo, G.; Sahoo, S. P.; Poulton, C. A.; Tsai, T. Y. R.; Wiesner, K. Tetrahedron 1980, 36, 719. (c) Blount, J. F.; Gray, G. D.; Atwal, K. S.; Tsai, T. Y. R.; Wiesner, K. Tetrahedron Lett. 1980, 21, 4413. (d) Valenta, K.; Grein, F. Can. J. Chem. 1982, 60, 601.

8. (a) ref. 2e; (b) Schmoldt, P.; Mattay, J. Synthesis 2003, 7, 1071.

9. Hon, Y.-S.; Chang, F.-J.; Lu, L.; Lin, W.-C. Tetrahedron 1998, 54, 5233.

10. (a) Kitahara, T.; Mikaye, M.; Kido, M.; Mori, K. Tetrahedron: Asymmetry 1990, 1, 775. (b) Paquette, L. A.; Maleczka, R. E.; Qiu, F. J. Org. Chem. 1991, 56, 2455.

11. The formation, in milder experimental conditions (THF/1N HCl 1.25/1, r. t., 3h) than those usually reported for acid catalyzed intramolecular aldol condensation, of an unsaturated hemiacetal, resulting from the addition of the enolized formyl group to the ketone carbonyl group, has been described. ${ }^{2 \mathrm{~m}}$

12. Mori, K.; Matsushima, Y. Synthesis 1993, 406.

13. De Santis, B.; Iamiceli, A. L.; Marini Bettolo, R.; Migneco, L. M.; Scarpelli, R.; Cerichelli, G.; Fabrizi, G.; Lamba, D. Helv. Chim. Acta 1998, 81, 2375.

14. In a recent work it was pointed out that 6-exo-hydroxybicyclo[2.2.2]octan-2-one selfassembles in the solid state through intermolecular hydrogen bonds to form a supramolecular helix: Sarvary, I.; Johansson, M. H.; Frejd, T. Cryst. Eng. Comm. 2002, 4(26), 146.

15. Ouellette, R. J.; Booth, G. E. J. Am. Chem. Soc. 1965, 30, 423.

16. A referee is pointing out that the $0.6 \mathrm{kcal} / \mathrm{mol}$ energy difference between the endo and the exo isomer corresponds to the A value for the OH group. ${ }^{17}$

17. E. L. Eliel, S. H. Wilen, L. N. Mander Stereochemistry of Organic Compounds; John Wiley \& Sons, Inc.: New York ,1994; p 695.

18. Under the adopted thioacetalization reaction conditions no epimerization occurs.

19. Marini Bettolo, R.; Migneco, L. M.; Moretti, P.; Scarpelli, R. J. Prakt. Chem. 1999, 341, 687.

20. (a) Neverov, A. A.; McDonald, T.; Gibson, G.; Brown, R. S. Can. J. Chem. 2001, 79, 1704.

(b) Brown, R. S.; Neverov, A. A. J. Chem. Soc., Perkin Trans. 1 2002, 2, 1039.

21. Di Stefano, S.; Leonelli, F.; Garofalo, B.; Mandolini, L.; Marini Bettolo, R.; Migneco, L. M. Org. Lett. 2002, 4, 2783. 